NIST

PUBLICATIONS

\section{DISCOUNT-A Program} for Discounting Computations in Life-Cycle Cost Analyses

\section{User's Guide and Reference} Manual

\section{Stephen R. Petersen}

U.S. DEPARTMENT OF COMMERCE Natlonal Institute of Standards and Tochnology Office of Appiled Economlcs Computing and Applled Mathematles Laboratory

Galthorsburg, MD 20899

Sponsored by

The Federal Energy RAanagement Program U.S. Department of Energy Washington, DC 20585

QC

100

.056

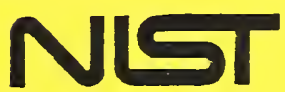

非 4513

1991

C. 2 



\section{DISCOUNT-A Program for Discounting Computations in Life-Cycle Cost Analyses}

\section{User's Guide and Reference Manual}

\section{Stephen R. Petersen}

U.S. DEPARTMENT OF COMMERCE Natlonal Institute of Standards and Technology Offlce of Applled Economles Computing and Appllod Mathematics Laboratory

Galthersburg, MD 20899

Sponsored by

The Federal Energy Management Program U.S. Department of Energy

Washington, DC 20585

January 1991

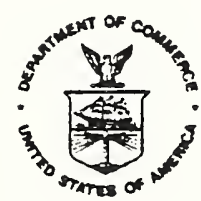

U.S. DEPARTMENT OF COMMERCE Robert A. Mosbacher, Secretary NATIONAL INSTITUTE OF STANDARDS AND TECHNOLOGY

John W. Lyons, Director 



\section{ABSTRACT}

The DISCOUNT program computes discount factors and related present values, future values, and periodic payment values of cash flows occurring at known points in time. DISCOUNT computations are especially useful in life-cycle cost analysis, financial analysis, and engineering-economics problems not requiring comprehensive summation and reporting. DISCOUNT performs all of the functions of standard discounting tables, computing present values of future amounts, future values of present amounts, present and future values of periodic payments, and periodic payments corresponding to present and future amounts. In addition, DISCOUNT computes the present value of periodic payments which increase at known rates over time, and the present value of energy costs which increase at rates projected by the U.S. Department of Energy for use in Federal life-cycle cost analyses. DISCOUNT provides the added flexibility of accepting non-integer discount rates, time periods, and escalation rates in its computations. DISCOUNT runs on most IBM PC and compatible microcomputers with no special equipment requirements. 


\section{PREFACE}

The DISCOUNT computer program, version 3.0 , has been prepared as an aid to implementing life-cycle cost evaluations of potential energy conservation and renewable energy projects in new and existing Federal buildings. It can also be used for evaluating similar projects in the private sector and at the state and local government levels.

DISCOUNT is the fourth of a four-volume set of reports which together provide a comprehensive set of methods, data, and computational tools for economic evaluation of such projects. Included in the four-volume set are the following:

\section{(1) Life-Cycle Costing Manual for the Federal Energy Management Program,} National Institute of Standards and Technology, Handbook 135 (revised 1991).

Handbook 135 is a guide to understanding life-cycle costing and related methods of economic analysis as they are applied to Federal decisions. It describes the required procedures and assumptions, defines and explains how to apply and interpret economic performance measures, gives examples of Federal decision problems and their solutions, explains how to use the energy price indices and discount factors which are updated annually in the supplement (2), and provides worksheets and other computational aids and instructions for calculating the required measures.

(2) Energy Prices and Discount Factors for Life-Cycle Cost Analysis, National Institute of Standards and Technology, (Annual Supplement to NIST Handbook 135 and NBS Special Publication 709), NISTIR 85-3273-5 (revised $10 / 90$ and updated annually).

This report, which is updated annually, gives the energy price and discount factor multipliers needed to estimate the present value of energy and other future costs. The data are based on energy price projections developed by the Energy Information Administration of the U.S. Department of Energy. Request the latest edition.

(3) The NIST "Building Life-Cycle Cost" (BLCC) computer program (version 3.0), National Institute of Standards and Technology, January 1991.

The Building Life-Cycle Cost (BLCC) computer program, version 3.0 , has been prepared as an aid to implementing life-cycle cost evaluations of potential energy conservation and renewable energy projects in new and existing Federal buildings. It can also be used for evaluating similar projects in the private sector and at the state and local government levels. BLCC 3.0 supersedes and incorporates both the Federal Building Life-Cycle Cost (FBLCC) and the National Bureau of Standards Life-Cycle Cost (NBSLCC) programs. For the economic analysis of energy conservation investments in Federal buildings, BLCC complies with NBS Handbook 135, Life-Cycle Cost Manual for the Federal Energy Management Program. For other investments in Federal buildings, BLCC complies with OMB Circular A-94, "Discount Rate to Be Used in Evaluating Time- 
distributed Costs and Benefits," March 27, 1972. BLCC complies with the American Society for Testing and Materials (ASTM) standard practices for building economics, including E917 (Practice for Measuring Life-Cycle Costs of Buildings and Building Systems), E964 (Practice for Measuring Benefit-to-Cost and Savings-to-Investment Ratios for Buildings and Building Systems), E1057 (Practice for Measuring Internal Rates of Return for Investments in Buildings and Building Systems), and E1074 (Practice for Measuring Net Benefits for Investments in Buildings and Building systems).

(4) DISCOUNT--A Program for Discounting Computations in Life-cycle Cost Analyses (version 3.0), NISTIR 4513, National Institute of Standards and Technology, 1991.

The DISCOUNT program computes discount factors and related present values, future values, and periodic payment values of cash flows occurring at known points in time. DISCOUNT computations are especially usefuI in Iife-cycle cost analysis, financial analysis, and engineering-economics problems not requiring comprehensive surmation and reporting. DISCOUNT performs all of the functions of standard discounting tables, computing present values of future amounts, future values of present amounts, present and future values of periodic payments, and periodic payments corresponding to present and future amounts. In addition, DISCOUNT computes the present value of periodic payments which increase at known rates over time, and the present value of energy costs which increase at rates projected by the U.S. Department of Energy for use in Eederal life-cycle cost analyses. DISCOUNT provides the added flexibility of accepting non-integer discount rates, time periods, and escalation rates in its computations. DISCOUNT runs on most IBM PC and compatible microcomputers with no special equipment requirements.

Both BLCC 3.0 and DISCOUNT 3.0 access DOE energy price escalation rates from the same two files (currently ENCOST90.SEQ and ENCOST90.RAN). These files are updated and released at the same time that NISTIR 85-3273, Energy Prices and Discount Factors for Life-Cycle Cost Analysis, is released each year. These disk files ensure that BLCC and DISCOUNT are compatible with computations performed using the factors in NISTIR 85-3273.

For convenience, the BLCC 3.0 and DISCOUNT 3.0 programs are packaged and distributed together on two $360 \mathrm{~K}$ disks in MS-DOS format. Text file versions of both user's guides are included on these disks.

For representatives of Federal government agencies and contractors to the Federal government, these publications can be ordered from:

Advanced Sciences, Inc.

2000 North 15 th Street

Suite 407

Arlington, VA 22201

(703) $243-4900$

Please request the publications by name and number. 
For others interested in obtaining the BLCC and DISCOUNT programs, please contact one of the following organizations:

National Technical Information Service

5285 Port Royal Road

Springfield, VA 22161

(703) $487-4650$

PC Software Interest Group

1030 Dast Duane Avenue

Sunnyvale, CA 94086

(408) 730-9291

MTS Software

5 Oak Forest Court

Saint Charles, MO 63303

(314) 441-1022

Workshops on the life-cycle costing method and energy analysis are conducted at locations around the country each year. The workshops include training and software for both BLCC and an energy analysis computer program called "A Simplified Energy Analysis Method" (ASEAM). A schedule of workshops can be obtained from the Office of Applied Economics, National Institute of Standards and Technology, Bldg. 101, Room A415, Gaithersburg, MD 20899, (301) 975-6132.

An introduction to the workshop is provided in a video training film, "LeastCost Energy Decisions: An Introduction to Life-Cycle Cost Analysis." The video film and companion workbook can be ordered from Video Transfer, Inc., 5709-B Arundel Avenue, Rockville, MD 20852, (301) 881-0270. Additional training films in the series are in preparation.

Further information on the Federal Energy Management Program can be obtained from the Federal Energy Management Program Staff, Office of the Assistant Secretary for Conservation and Renewable Energy, U.S. Department of Energy. Please direct communication to: FEMP, CE 10.1, U.S. Department of Energy, 1000 Independence Avenue, SW, Washington, D.C. 20585. 


\section{ACKNOWLEDGMENTS}

The author wishes to thank Mr. Richard W. Brancato and Mr. K. Dean DeVine of the Federal Energy Management Program of the U.S. Department of Energy (DOE) for their continued support and direction of this work. Appreciation is also extended to Harold Marshall, Rosalie Ruegg and Sieglinde Fuller of the Office of Applied Economics and Gregory Tassey of the NIST Program Office for their careful review of this User's Guide. 
1. INTRODUCTION • . . . . . . . . . . . . . . . . . . . . . . . . . .

2. INSTALLATION AND FILE REQUIREMENTS . . . . . . . . . . . . . . . . . . . 3

3. RUNNING DISCOUNT • . . . . . . . . . . . . . . . . . . . . . . . . . . . 3

4. COMPUTATIONAL METHODS. . . . . . . . . . . . . . . . . . . . . . . . . . 8

\section{List of Figures}

Figure 1. Discounting applications menu. . . . . . . . . . . 2

Figure 2. Selecting Terms to be Defined. . . . . . . . . . 2

Figure 3. Present Value when Future Value is Known ......... 4

Figure 4. Uniform Periodic Payment when Present Value is Known . . . 4

Figure 5. Present Value of a Non-Uniform Periodic Amount Increasing at a Constant Escalation Rate. . . . . . . . . . . 5

Figure 6. Present Value of a Non-Uniform Periodic Amount Increasing at a Changing Escalation Rate... . . . . . . . . . 6

Figure 7. Present Value of Annually Recurring Energy Expenditures Using DOE's Projected Energy Price Escalation Rates . . . . 7

Figure 8. DOE Energy Price Escalation Rates Used in Example. . . . 8 


\section{INTRODUCTION}

The DISCOUNT program provides a convenient method of computing many of the values and factors needed for life-cycle cost analyses, engineering-economic analyses, and financial analyses. DISCOUNT performs the functions of standard discounting tables, computing present values of future amounts, future values of present amounts, present and future values of periodic payments, and periodic payments corresponding to present and future amounts. In addition, DISCOUNT computes the present value of periodic payments which increase at known rates over time, and the present value of energy costs which increase at rates projected by the U.S. Department of Energy (DOE) for use in life-cycle cost analyses of buildings and building systems owned or operated by the Federal government. The DOE projections of energy price increases are in data files included with the DISCOUNT program and are automatically retrieved from the disk as needed. These data files are updated annually by NIST, following release of the new projections by DOE.

DISCOUNT provides the added flexibility of using non-integer discount rates, time periods, and escalation rates in its computations. All computations are made using double-precision mathematics. Dollar values up to $\$ 999,999,999,999.99$ can be accurately calculated. Definitions of terms used in the DISCOUNT program can be displayed on the screen as needed. These features make the DISCOUNT considerably more useful and accurate than even the most voluminous standard tables of discount factors.

An end-of-year discounting convention is used in DISCOUNT. That is, all cash flows are assumed to be incurred at the end of each time period and are discounted from that point in time. Interest compounding through multiple time-periods occurs once per time period. Thus, if each time period represents one year, compounding occurs once per year. If each time period represents one month, compounding occurs 12 times per year.

Figure 1 shows the discounting applications menu, which lists the discounting operations performed directly by DISCOUNT. The desired operation is selected by highlighting the application and pressing <Enter> or by entering its corresponding application number (1-9). Additional discounting functions are possible by using a combination of operations. All relevant input variables and computational results are maintained in memory from application to application. Thus, after finding the present value of annually recurring costs which escalate at some known rate (applications 7,8 , and 9), the

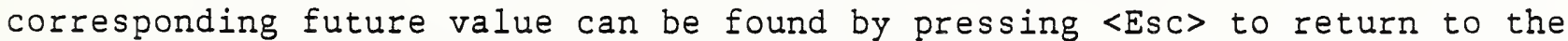
main menu. Then select application 2 (future value of a present value amount) and press the <Enter> key for each of the values displayed: the present value amount, number of time periods, and discount rate. The future value of these annually recurring costs will then be displayed.

Figure 2 shows a list of terms used in the DISCOUNT program that can be defined on the screen. Press ' $D$ ' to display the list; use the up and down arrows to highlight the term to be defined and press <Enter>. Most of the definitions used are from ASTM E 833-89, "Standard Terminology of Building Economics." 


\section{SINGLE AMOUNTS}

1. PRESENT VALUE when future value is known.

2. FUTURE VALUE when present value is known.

$$
\text { UNIFORM SERIES OF PAYMENTS }
$$

3. PRESENT VALUE when periodic payment amount is known.

4. FUTURE VALUE when periodic payment amount is known.

5. PERIODIC PAYMENT AMOUNT when present amount is known.

6. PERIODIC PAYMENT AMOUNT when future amount is known.

$$
\text { NON-UNIFORM SERIES OF PAYMENTS }
$$

7. PRESENT VALUE when periodic payment amount increases at constant rate.

8. PRESENT VALUE when periodic payment amount increases at changing rate.

9. PRESENT VALUE using DOE energy price escalation rates.

Figure 1. Discounting applications menu.

Base Year

Discount Rate

Escalation Rate

Future Value

Non-Uniform Series

Periodic Payment Amount

Present Value

Study Period

Time Period

Uniform Series

Figure 2. Selecting Terms to be Defined.

DISCOUNT is intended to be used for assistance in discounting individual cost components in an economic analysis. If more comprehensive analysis and reporting are required, including summation of cash flows on a time-equivalent basis and computation of economic decision factors for alternative investments (e.g., net savings, savings-to investment ratio, or adjusted internal rate of 
return), a life-cycle cost program such as the NIST Building Life-Cycle Computer Program (BLCC version 3.0) may be more appropriatel.

\section{INSTALLATION AND FILE REQUIREMENTS}

DISCOUNT can be run directly from the original disk or installed on a hard disk. Once loaded, DISCOUNT runs equally fast from a hard drive or from the original disk, except when accessing the DOE energy price projections from the disk (application 9 only). If it is to be run from the original disk, it is suggested that this disk be copied and the copy be used. If it is to be installed on a hard disk, use the Change Directory command (CD) to move to the (sub)directory where it is to be installed. Then place the original disk in the A drive and type 'COPY A:*.*' to copy the files to the hard disk: DISCOUNT.EXE, ENCOST90.RAN, ENCOST90.SEQ, and DISCOUNT.DOC. DISCOUNT.EXE is the executable program file. The two ENCOST9O files contain the DOE energy price escalation rates used with discounting application 9 only. (These are the same files used with the NIST BLCC program (version 3.0). The DISCOUNT.DOC file is the name of the data file containing this user's guide and reference manual.

DISCOUNT does not require graphics capability, math coprocessor, or other special hardware to run.

\section{RUNNING DISCOUNT}

To run DISCOUNT from the current directory, type DISCOUNT at the DOS ready prompt. After reading the initial screen, press any key to bring up the main discounting applications menu, as shown in figure 1. Use the cursor arrows to highlight the application desired, and press <Enter>, or simply press the application number (1-9). To see the definition of any term shown in figure 2 , press "D", and then highlight the term to be defined and press <Enter>. Press "Q" to quit the program and return to DOS.

For discounting applications 1 through 7 , the data entry form will appear on the screen in a format similar to that shown in figure 3 . Enter the parametervalues requested on the screen, pressing <Enter> or the up or down cursor key after each entry. Once all values are entered, the answer will appear below the box. A change in any of the parameters will immediately change the answer shown. IMPORTANT: The <Enter> or the up or down cursor keys MUST be pressed to effect this change.

1 Petersen, S. R., The NIST Building Life-Cycle Cost (BLCC) Program (version 3.0), NISTIR 4481, National Institute of Standards and Technology, Gaithersburg, MD, January 1991. 


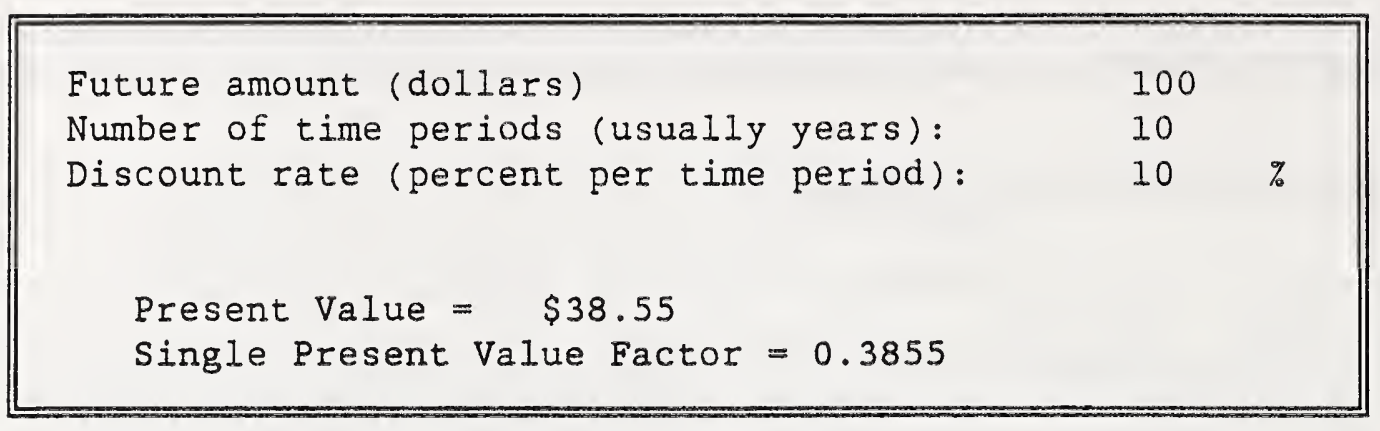

Figure 3. Present value when future value is known.

When entering dollar values, do not use the dollar sign ( $\$$ ) or commas. When entering discount or escalation rates, enter them in percentage terms, not in decimal form. For example, 10 percent is entered as 10 , not 0.10 . Do not include the percent (\%) sign.

If fractional time periods (e.g., 10.5) are entered for applications with uniform or non-uniform series of payments (applications 3-9), a corresponding fractional payment is assumed in the final period. For example, if the present value of annual maintenance costs is to be calculated over 10.5 years, and $\$ 100$ is the annual cost, then the final half-period maintenance cost is assumed to be $\$ 50(0.5 \cdot \$ 100)$. If the periodic payment increases at a specified escalation rate per time period, then the payment in the final fractional time period is assumed to be $P \cdot f \cdot(1+e)^{f}$, where $P$ is the payment amount at the end of the last full (integer) time period, $f$ is the fractional time period, and $e$ is the escalation rate for the fractional period.

If time periods other than one year are used, the discount (interest) rate must reflect the rate for the period actually used and not the annual rate. For example, if the monthly payment on a $\$ 100,000$ loan over 30 years at $12 \%$ annual interest ( $1 \%$ monthly) is desired, press 5, "Uniform periodic payment when present value is known." Enter 100000 for the present amount, 360 (30 years - 12 months per year) for the number of time periods and 1 for the monthly interest (discount) rate. This example is shown in figure 4. (Note: because of compounding effects, the sum of 12 monthly payments is not the same as the annual payment calculated using 30 years and 12 percent interest.)

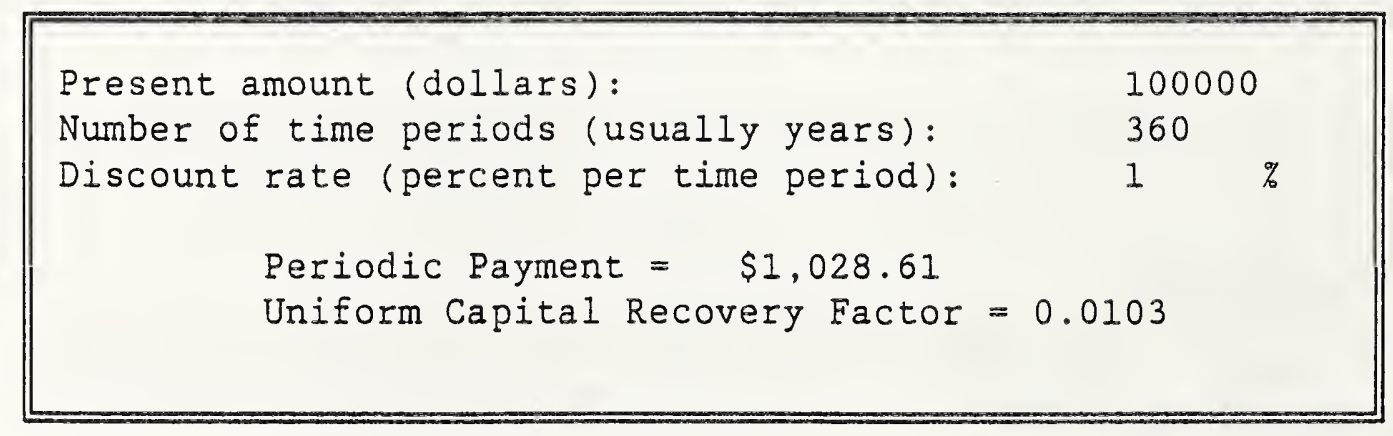

Figure 4. Uniform periodic payment when present value is known. 
For the calculation of the present value of a non-uniform series of payments, starting with an initial amount changing from period to period at a constant rate (application number 7 ), the escalation rate (i.e, the periodic rate of change in the periodic amount) must be entered. See figure 5 for an example of this application. In this example, an annual payment which has a value of $\$ 100$ initially, but increases at $5 \%$ per year over 30 years and is discounted at $10 \%$, has a present value of $\$ 1,579.86$. Note that the first payment (at the end of year 1 ) is actually $\$ 105.00$ (not $\$ 100.00$ ), since the escalation rate is applied uniformly in every year.

\begin{tabular}{||lll||}
\hline Initial periodic amount (base year dollars): & 100.00 \\
Number of time periods (usually years): & 30 & \\
Discount rate (percent per time period): & 10 & $\%$ \\
Escalation rate (percent per time period): & 5 & $\%$ \\
Present Value $=$ \$1,579.86 & \\
Uniform Present Value Factor $=15.799$
\end{tabular}

Figure 5. Present value of a non-uniform periodic amount increasing at a constant escalation rate.

For the calculation of the present value of a non-uniform series of payments, starting with a known initial amount and changing from period to period at a changing rate (application number 8 ), up to ten rates of change and the duration in consecutive time periods can be entered. (The number of rates entered cannot exceed the number of periods in the analysis.) An example of this application is shown in figure 6 . After entering the initial payment amount, the total number of periods in the analysis, and the discount rate, the number of escalation rates to be used is entered (1-10). Then a separate box will appear on the screen, in which the escalation rates and corresponding duration (number of consecutive time periods for each rate) are to be entered.

The total number of periods for these escalation rates must add up to the total number of time periods specified for the analysis. (If a non-integer number of time periods is used, then the total number of periods for the escalation rates must equal the total number of time periods in the analysis, rounded up to the next integer.) Press <EsC when the escalation rates and number of periods each have been entered and the answer will be displayed.

If the number of time periods in the analysis is changed, the number of periods must also be changed for at least one of the escalation rates to make the total number of periods correspond. To move into the escalation rate box, move the cursor to the "number of escalation rates to be used" and press $<$ Enter $>$. 
Initial periodic amount (base year dollars): 100

Number of time periods (usually years): $\quad 30$

Discount rate (percent per time period): $10 \%$

Number of Escalation Rates to be used $(1-10): 3$

$\begin{gathered}\text { Escalation } \\
\text { Rate }(\%)\end{gathered}$
$\begin{gathered}\text { Number of } \\
\text { Periods }\end{gathered}$
\begin{tabular}{lll}
$1:$ & 5 & 10 \\
3 & 3 & 10 \\
$3:$ & 2 & 10 \\
\hline
\end{tabular}

PRESENT VALUE $=\$ 1,446.35$

Modified Uniform Present

Value Factor $=14.464$

Figure 6. Present value of a non-uniform periodic amount increasing at a changing escalation rate.

Figure 6 shows the present value of a non-uniform series of annual payments over 30 years, valued at $\$ 100$ initially (i.e., at the beginning of the first time period), and increasing at $5 \%$ per year for the first 10 years, $3 \%$ for the next 10 years, and $2 \%$ for the final 10 years. This kind of discounting operation is frequently used in energy cost analyses, when the periodic rate of energy price increase is expected to vary over time instead of remaining constant.

To calculate the present value of a series of annual energy costs, starting with a known initial amount, and increasing annually at rates projected by the U.S. Department of Energy, use application number 9. An example of this discounting application is shown in figure 7 .

Because the DOE forecasts vary with region, rate type, energy type, base year, each of these must be specified. There are four DOE regions: (1) North East, (2) North Central, (3) South, and (4) West. The states in each region are displayed on the screen when the cursor is located on the region field. There are three energy rate types: (1) residential, (2) commercial, and

(3) industrial. And there are six energy types: (1) electricity,

(2) distillate fuel oil, (3) residual fuel oil, (4) natural gas, (5) LPG, and

(6) coal. Not all combinations of rate types and energy types have DOE projections. There are no DOE projections for residential coal or residual fuel oil, or for commercial and industrial LPG. An error message will be displayed if one of these combinations is entered.

The escalation rates for energy prices projected by DOE vary from year to year, and thus the base year must be specified. The base year must be in the range 1990 to 2000. The initial energy cost must be specified in base-year dollars, and all future costs will be discounted to the beginning of this base year. 
The DOE projections of energy price escalation rates do not include general inflation; that is, they are in real terms. If the analysis is to include general inflation, then the user must specify the underlying average rate of inflation over the period of analysis. If the analysis does not include inflation, then set the general inflation rate to 0 . If inflation is included, the discount rate should reflect this same inflation rate. If inflation is excluded, general inflation should be excluded from the discount rate. Note that the nominal discount rate (i.e., including inflation) is not simply the sum of the real discount rate (excluding inflation) and the underlying general inflation rate, but is calculated as ${ }^{2}$ :

$D=d+I+d I$

where $D=$ the nominal discount rate,

$\mathrm{d}=$ the real discount rate,

$I=$ the underlying rate of general inflation.

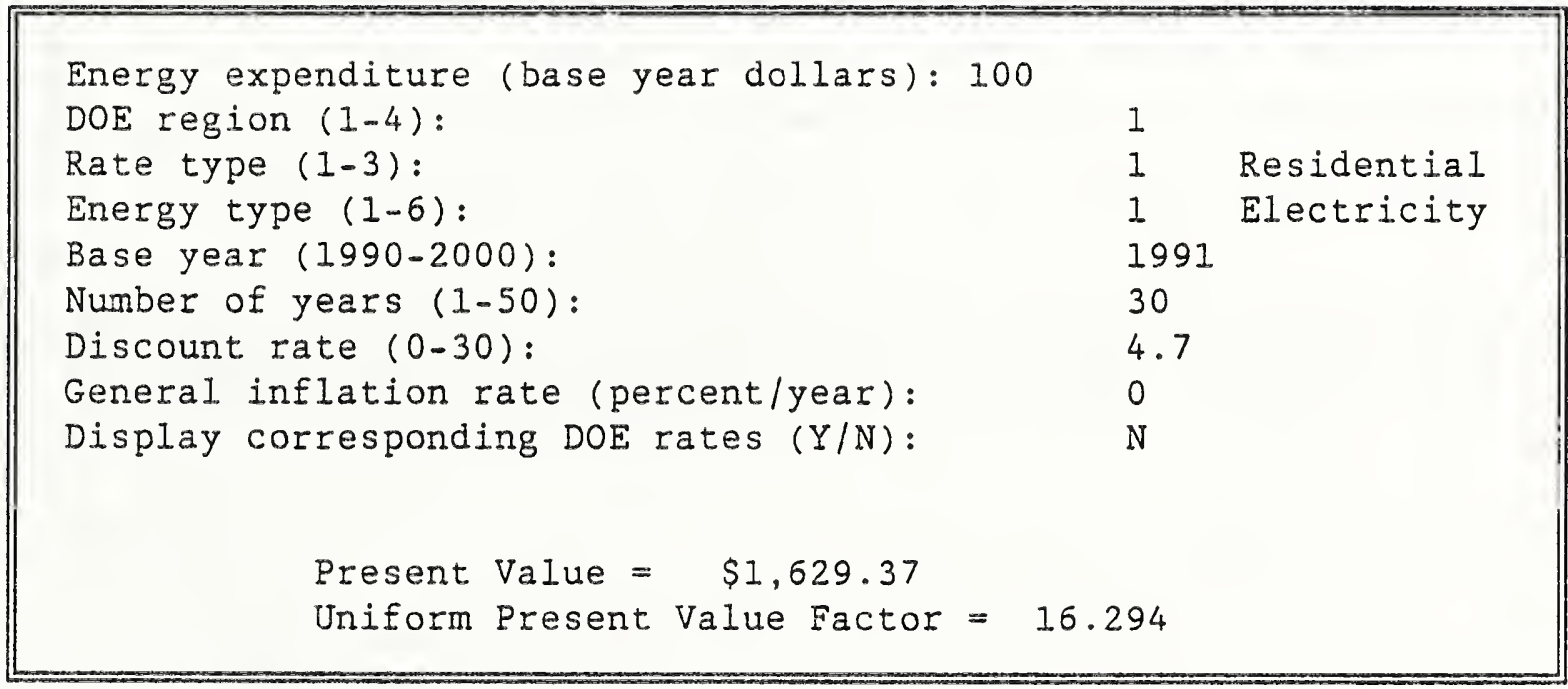

Figure 7. Present value of annually recurring energy expenditures using DOE's projected energy price escalation rates.

The DOE rates used in this last analysis can be displayed on the screen by moving the cursor to the "Display corresponding DOE rates" field and pressing "Y". Figure 8 shows the rates corresponding to the example in figure 7 . If the analysis is performed with a non-zero general inflation rate, the rates displayed will include this rate. Note that, as with the discount rate, the compounding effect of real price increases with the rate of general inflation must be considered, so that

$$
E=e+I+e I
$$

2 The additional cross product (dI) results from the compounding effect of general inflation and the real discount rate, i.e., $D=(I+d)(I+I)-1$. 


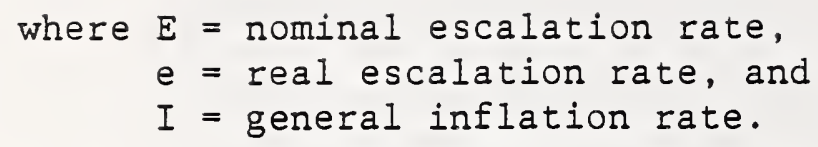

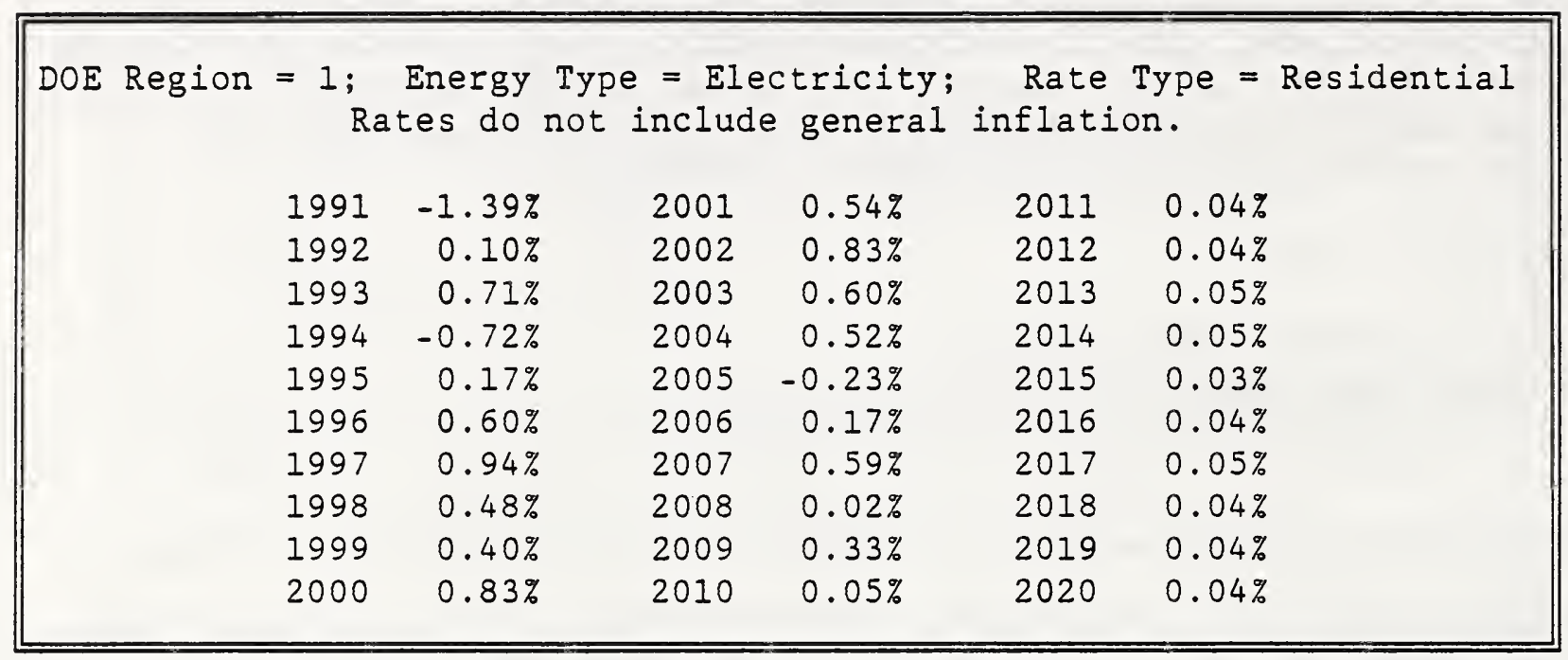

Figure 8. DOE energy price escalation rates used in example.

The DOE projections of energy price increases do not extend beyond the year 2029. For any year beyond 2029, the rate of change used in the analysis is set to the rate of general inflation, or zero if no inflation is specified.

\section{COMPUTATIONAL METHODS}

The equations used to calculate the various discounting factors and the corresponding dollar amounts in DISCOUNT are documented here. Equations $I$ and 2 can be used with an integer or non-integer number of time periods. For equations 3 through 9, which include periodic payment amounts, the use of a non-integer number of time periods requires special treatment. In these latter equations, the final payment is assumed to be a fraction of the periodic payment, corresponding to the length of the fractional period. The use of standard discounting equations having periodic payment amounts and a non-integer number of payment periods will lead to erroneous results.

Notation used in the following equations:

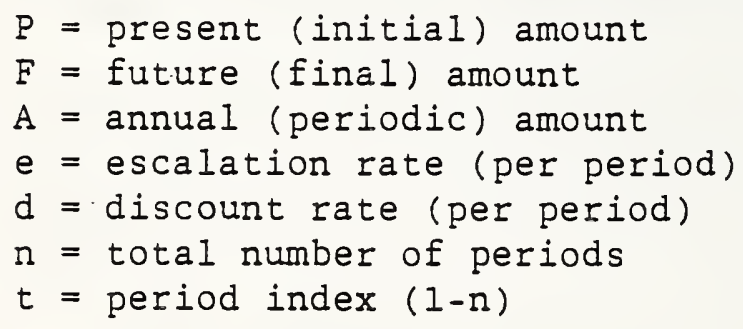


Note that $d$ and $e$ can be in either real or nominal terms, but when used together they must be consistent. Do not mix real and nominal rates in the same analysis.

Discounting applications:

(1) Present value when future value is known:

$P=F \cdot$ Single Present-Value factor (SPV)

$S P V=1 /(1+d)^{n}$

(2) Future value when present value is known:

$F=\mathrm{P} \cdot$ Single Compound Amount factor (SCA)

$\mathrm{SCA}=(1+d)^{\mathrm{n}}$

(3) Present value when uniform periodic payment amount is known:

$F=A \cdot$ Uniform Present Value factor (UPV)

$\mathrm{UPV}=\mathrm{n} \quad$ for $\mathrm{d}=0$, and

$U P V=\underline{(1+d)^{n}-1}$ for $d \neq 0$ and integer values of $n$.

$d(1+d)^{n}$

For $d \neq 0$ and non-integer values of $n$, use equation $3 b$ to compute UPV for the integer value of $n$; then adjust UPV as follows:

$$
U P V=U P V+\frac{\text { fraction }}{(1+d)^{n}}
$$

where fraction = the difference between $\mathrm{n}$ and the integer value of $\mathrm{n}$. 
(4) Future value when uniform periodic payment amount is known:

$$
\begin{aligned}
F & =A \cdot \text { Uniform Compound Amount factor (UCA) } \\
U C A & =n \quad \text { for } d=0 \text {, and } \\
U C A & =\frac{(1+d)^{n}-1}{d} \text { for } d \neq 0 \text { and integer values of } n .
\end{aligned}
$$

For $d \neq 0$ and non-integer values of $n$, use equation $4 \mathrm{~b}$ to compute UCA for the integer value of $\mathrm{n}$; then adjust the UCA factor as follows:

$$
\mathrm{UCA}=\mathrm{UCA} \cdot(1+\mathrm{d})^{\text {fraction }}+\text { fraction }
$$

where fraction = the difference between $\mathrm{n}$ and the integer value of $\mathrm{n}$.

(5) Uniform periodic payment amount when initial (present) amount is known:

$$
\begin{aligned}
A=P \cdot \text { Uniform Capital } & \text { Recovery factor (UCR) } \\
U C R=1 / n & \text { for } d=0 \text {, and } \\
U C R=\frac{d(1+d)^{n}}{(1+d)^{n}-1} & \text { for } d \neq 0 \text { and integer values of } n .
\end{aligned}
$$

For $d \neq 0$ and non-integer values of $n$, first compute UPV using equations $3 b$ and $3 c$. Then

$$
\mathrm{UCR}=1 / \mathrm{UPV}
$$

(6) Uniform periodic payment amount when final (future) amount is known:

$$
\begin{aligned}
A=F \cdot \text { Uniform Sinking } & \text { Fund factor (USF) } \\
U S F=1 / n & \text { for } d=0 \text {, and } \\
U S F=\frac{d}{(1+d)^{n}-1} & \text { for } d \neq 0 \text { and integer values of } n .
\end{aligned}
$$


For $d \neq 0$ and non-integer values of $n$, first compute UCA using equations $4 \mathrm{~b}$ and $4 \mathrm{c}$. Then

$\mathrm{USF}=1 / \mathrm{UCA}$.

(7) Present value when periodic payment amount increases from period to period at a constant rate:

For integer values of $n$ :

$$
P=A_{0} \cdot \text { Modified Uniform Present Value factor (UPV*) }
$$

where:

$$
A_{0}=\text { initial periodic amount (base year dollars) }
$$

$\mathrm{UPV} *=\mathrm{n}$ when $e=d$, and

$$
U P V^{*}=\left[\frac{(1+e)}{(d-e)}\right] \cdot\left[1-\left[\begin{array}{c}
(1+e) \\
(1+d)
\end{array}\right]^{\mathfrak{n}}\right] \quad \text { when } e \neq d
$$

For $d \neq 0$ and non-integer values of $n$, use equation $7 b$ to compute UPV* for the integer value of $n$; then adjust the UPV* factor as follows:

$$
\mathrm{UPV}^{*}=\mathrm{UPV}^{*}+\text { fraction } \cdot\left[\frac{(1+e)}{(1+d)}\right]^{\mathfrak{n}} \text {. }
$$

(8\& 9) Present value when periodic payment amount increases from period to period at a changing rate. The same computational methods are used when the escalation rates are entered by the user and when the escalation rates are retrieved from the DOE data files on the disk. For the former, the periodic rate may be the same over several time periods. For the latter, the periodic (annual) rate changes every year.

For integer values of $\mathrm{n}$ :

$P=A_{0} \cdot$ Modified Uniform Present Value factor (UPV*)

$$
\begin{aligned}
& \text { UPV* }=\begin{array}{ll}
\mathrm{n} \quad \text { Index }_{\mathrm{t}} & \\
\end{array} \\
& t=1(1+d)^{t}
\end{aligned}
$$




$$
\begin{aligned}
\text { where Index } & =\prod_{j=1}^{t}\left(1+e_{j}\right) \text {, and } \\
e_{j} & =\text { the escalation rate in period } j .
\end{aligned}
$$

For non-integer values of $n$, use equations $8 a$ and $8 b$ to compute UPW* for the integer value of $\mathrm{n}$; then adjust the UPV* factor as follows:

$$
\mathrm{UPV} *=\mathrm{UPV} *+\text { fraction } \cdot \frac{\operatorname{Index}_{\mathrm{k}} \cdot\left(1+e_{\mathrm{k}+1}\right)^{\text {fraction }}}{(1+d)^{\mathrm{n}}},
$$

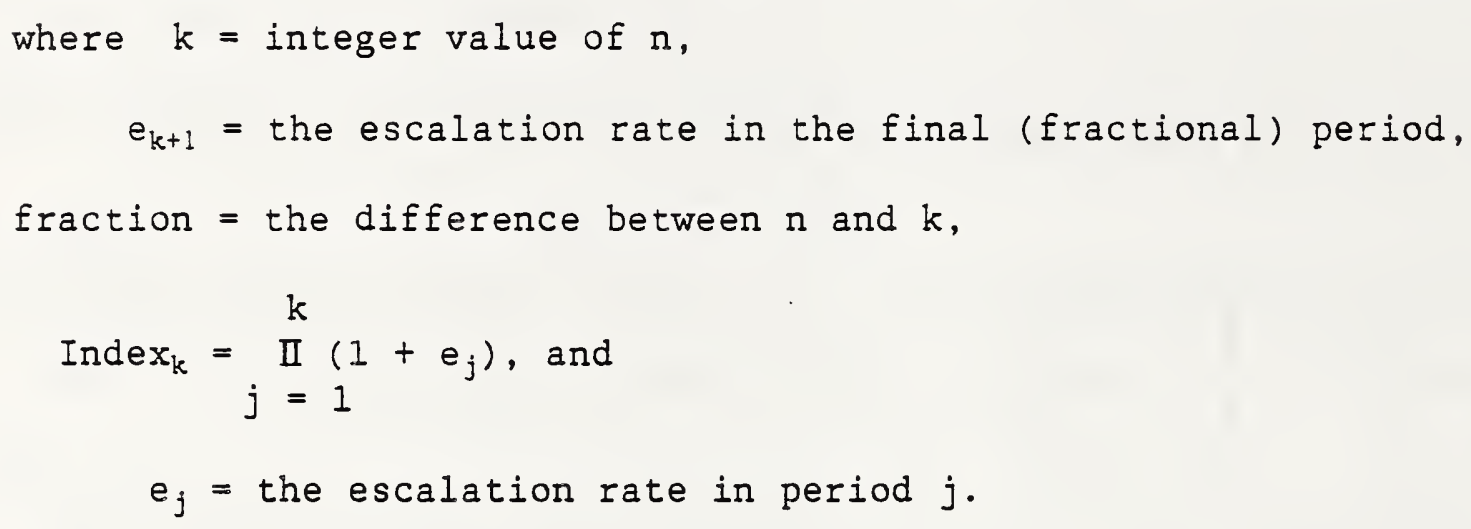




\begin{tabular}{|c|c|c|}
\hline \multirow{3}{*}{$\begin{array}{l}\text { NIST-114A } \\
\text { (REV. 3-90) }\end{array}$} & \multirow{2}{*}{$\begin{array}{l}\text { U.S. DEPARTMENT OF COMMERCE } \\
\text { NATIONAL INSTITUTE OF STANDARDS AND TECHNOLOGY }\end{array}$} & $\begin{array}{r}\text { 1. PUBLCATION OR REPORT MUMBER } \\
\text { NISTIR } 4513\end{array}$ \\
\hline & & 2. PERFORMING OAGANIZATION REPORT NUMBER \\
\hline & \multirow[t]{2}{*}{ BIBLIOGRAPHIC DATA SHEET } & 3 PURUCATIOURATE \\
\hline & & JANUARY 1991 \\
\hline
\end{tabular}

DISCOUNT--A Program for Discounting Computations in Life-Cycle Cost Analyses

User's Guide and Reference Manual

5. AUTHOR(S)

Stephen R. Petersen

6. PERFORMING ORGANIZATION (IF JOINT OR OTHER THAN NIST, SEE INSTRUCTIONS)

U.S. DEPARTMENT OF COMMERCE

NATIONAL INSTITUTE OF STANDARDS AND TECHNOLOGY

CAITHERSBURG, MD 2089

7. CONTRACT/GRANT NUMBER

8. TYPE OF REPORT AND PERIOD COVERED

final

9. SPONSORINO ORGANIZATION MAME AND COMPLETE ADDRESS (STREET, CITY, STATE, ZIP)

U.S. Department of Energy

Federal Energy Management Program

1000 In dependence Avenue, S.W.

Washington, D.C. 20585

10. SUPPLEMENTARY NOTES

This report is comprised of both a computer program and user's guide. The user's guide is included as a file on the program disk.

11. ABSTRACT (A 200-WORD OR LESS FACTUAL SUMMARY OF MOST SIGMIFICANT IMFORMATION. IF DOCUMENT INCLUDES A SIGHIFICANT BIBLOGRAPHY OR UTERATURE SURVEY, MENTION IT HERE.)

The DISCOUNT program computes discount factors and related present values, future values, and periodic payment values of cash flows occurring at known points in time. DISCOUNT computations are especially useful in life-cycle cost analysis, financial analysis, and engineering-economics problems not requiring comprehensive summation and reporting. DISCOUNT performs all of the functions of standard discounting tables, computing present values of future amounts, future values of present amounts, present and future values of periodic payments, and periodic payments corresponding to present and future amounts. In addition, DISCOUNT computes the present value of periodic payments which increase at known rates over time, and the present value of energy costs whilch increase at rates projected by the U.S. Department of Energy for use in Federal life-cycle cost analyses. DISCOUNT provides the added flexibility of accepting non-integer discount rates, time periods, and escalation rates in its computations. DISCOUNT runs on most IBM PC and compatible microcomputers with no special equipment requirements.

12. KEY WORDS (6 TO 12 ENTRIES; ALPMABETICAL ORDER; CAPITAUZE ONLY PROPER MAMES; AND SEPARATE KEY WORDS BY SEMICOLONS)

annual value analysis; discount factors; discounting analysis; economic analysis; financial analysis; interest rate; present-value analysis

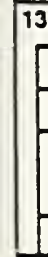

3. AVAILABIUTY

$\mathrm{X}$ UNUMITED

FOR OFFICLAL DISTRIBUTION. DO MOT RELEASE TO MATIONAL TECHHICAL INFORMATION SERVICE (NTIS).

ORDER FROM SUPERINTENDENT OF DOCUMENTS, U.S. GOVERNMENT PRINTING OFFICE, WASHINGTON, DC 20402.

ORDER FROM HATIONAL TECHMICAL IMFORMATION SERVCE (NTIS), SPRIMGFIELD, VA 22161.

14. NUMBER OF PRINTED PAQES

21

15. PAICE

$\mathrm{AO} 2$ 


